\title{
Challenges of Information and Communication Technology Utilization Among Undergraduate Community Health Nursing Students in Tanta University, Egypt
}

\author{
Umar Lawal Bello ${ }^{1}$, Lulah Abd Elwhab Abd Elaty Hassan ${ }^{2}$, Umar Yunusa $^{1, ~ *}$, Idris Abdulrashid ${ }^{1}$, \\ Ruqayya Hamza Usman ${ }^{1}$, Khadija Nuhu Nasidi ${ }^{1}$ \\ ${ }^{1}$ Department of Nursing Sciences, Faculty of Allied Health Sciences, Bayero University Kano, Kano, Nigeria \\ ${ }^{2}$ Department of Community Health Nursing, Faculty of Nursing, Tanta University, Tanta, Egypt
}

Email address:

uyunusa.nur@buk.edu.ng (U. Yunusa)

${ }^{*}$ Corresponding author

\section{To cite this article:}

Umar Lawal Bello, Lulah Abd Elwhab Abd Elaty Hassan, Umar Yunusa, Idris Abdulrashid, Ruqayya Hamza Usman, Khadija Nuhu Nasidi. Challenges of Information and Communication Technology Utilization Among Undergraduate Community Health Nursing Students in Tanta University, Egypt. American Journal of Nursing Science. Vol. 6, No. 3, 2017, pp. 274-279. doi: 10.11648/j.ajns.20170603.26

Received: March 22, 2017; Accepted: April 14, 2017; Published: May 25, 2017

\begin{abstract}
Information and communication technology (ICT) continues to rapidly progress and is integrated in practically all health care professional and research fields including nursing. It is essential that nurses and nursing students acquire competences to successfully utilize ICT in their education and practice to benefit patients and gain more satisfaction from their work. This study was conducted to explore the Challenges of Information and Communication Technology Utilization among Undergraduate community Health Nursing Students in Tanta University, Egypt. A descriptive cross sectional design was used for the study where the entire $4^{\text {th }}$ year students who registered with community health nursing departments were recruited (600 students) to participate. A response rate of $84 \%$ (504 students) was recorded. A validated structured questionnaire was used for data collection over a period of four weeks. The data collected were organized, tabulated and analysed using the Statistical Package for Social Science (SPSS) version 20. The results indicated that the challenges of utilizing ICT as stated by the students include slow/poor internet speed/access (84.3\%) and lack of ICT facilities (80.4\%) especially in the rural communities. Other challenges as stated by the respondents are difficulty in accessing the required information (68.7\%) and expensive internet subscription (68.5\%). The study concluded that the utilization of ICT among the respondents was associated with challenges. A significant challenge is the access to the required information and the lack of ICT facilities. It is therefore recommended that the faculty and the university management ensure adequate provision and maintenance of ICT devices to the students with corresponding accessibility.
\end{abstract}

Keywords: Challenges, Information, Communication, Technology, Utilization

\section{Introduction}

Information and communication technology (ICT) is a specific term that stresses the role of unified communications and the integration of telecommunications (telephone lines and wireless signals), computers as well as necessary enterprise software, storage, and audio-visual systems. It enables users to access, store, transmit, and manipulate information [1]. Information and communication technology continues to rapidly progress and is integrated in practically all health care professional and research fields including nursing. It is important that nurses and nursing students acquire competences to successfully employ ICT in their regular practice to benefit patients and gain more satisfaction from their work [2].

Significant transformations in higher education such as in nursing education as well as health sciences have occurred as a result of recent technological advancements [3-5]. Many international organizations have acknowledged Information and Communication Technology as a useful tool to address education in health care sector. Accordingly, most of the 
developed countries are investing heavily on ICT infrastructure and focusing on technology mediated learning approaches to match the changing learning styles among youth. Even developing countries are taking efforts to acknowledge the technological expansions. Health professional students now have a strong base to utilize information technology for their professional development [6].

In spite of the benefits of ICT in nursing education and research, it has been established that there are many challenges. These challenges may be related to teachers, students or both. It has also been established that most teachers have not taken the advantages in their teaching and professional development. The various reasons adduced for low utilization of ICT facilities in teaching-learning process are inadequacy of ICT facilities for the teeming population of teachers and students who need them, other reasons are poor and inadequate infrastructural support such as erratic electricity supply, poor internet services, low bandwidth, and poor maintenance of ICT facilities [7]. With regards to the challenges of students in the e-learning course environment, Al-Fadhli in 2008stated that a student needs to deal with the following new issues/challenges: the ability to deal with computer and internet technologies; undertaking tests and submitting assignments online; interacting with lecturers and students via the web; and reliance on self-learning approaches [8].

In a systematic review of literature conducted by Button (2013), many problems or challenges facing nursing students in ICT use in education and research such as the majority of the students are not skilful in internet usage; high cost reported as main obstacle for low internet penetration in students; lack of resources and skills to access more complex information literacy tasks is difficult to increased. Furthermore, nursing education is still not integrating the skill and knowledge base essential in pre-registration programs; time constraints and lack of knowledge about new and available technologies; lack of new and available technologies at the faculty and inadequate training and support on behalf of the faculty [9]. In addition, Childs et al identified barriers to the utilization of information technology in nursing education and research. They reported low level of skill and training; increased workload; not enough computers; poor technical support and lack of training. Other barriers include lack of recognition by all nurses that information technology is an integral part of nursing; technical infrastructures were unreliable; low funding required to achieve enhanced use of e-learning; and students had low perception of technical and faculty support for webenhanced learning [10].

Several problems were identified to be encountered by healthcare professionals while using ICT. These range from staff discomfort with new technology to those who are concerned that ICT threatens healthcare practice. Its future may well therefore depend on human and socioeconomic factors rather than the ability of the technology itself. Successful integration of ICT into existing structures requires organizations to develop policies, procedures, guidelines and strategies to guide and govern professionals and ensure patient and staff safety [11]. Effective planning is vital for effective implementation of ICT. Hardware should be compatible with each other and suitable for their purpose. Healthcare leaders and managers need to examine and, if appropriate, reconfigure entire systems of work, particularly where custom and practice may not be as efficient as is needed. Individual staff needs to examine his/her role and activities and minimize process duplication and waste [12].

The technology offers a mechanism for providing costeffective, targeted care but, before it is universally accepted, its benefits need to be demonstrated to providers, patient advocate groups and, perhaps above all, patients. Practitioners involved in delivering ICT services need to be aware of any leadership and management challenges that may influence service delivery. Other challenges to anticipate and deal with upfront might include poor management of expectations and needs of patients, relatives and fellow professionals promoting reliance on the technology support; reliance on the patients' recall and on reported rather than observed changes in signs and symptoms [13].

Many efforts to develop ICT-enabled care in rural areas and communities occur with too little community health nurses involvement. The lack of involvement of nurses in eHealth has important implications for the proposed expansion of the role of nurses which may involve greater use of eHealth [14]. Factors contributing to exclusion of nurses include lack of forethought by the planners of community health ICT projects, and the low ICT preparedness of many nurses. Thus, the nursing profession needs to address not only the frequent absence of nurses in planning processes for ICT enabled care, but also the development of nursing professionals who have the competence, skills, and vision to take leadership roles on interdisciplinary ICT teams [15]. This study is therefore conducted to explore the challenges to the utilization of ICT among undergraduate Community Health Nursing students of Tanta University, Egypt. This is with the view of identifying strategies of improving the utilization of ICT among the students.

\section{Methodology}

\subsection{Research Design and Instrument}

A Descriptive cross sectional design was used for the study. Data was collected with a validated structured questionnaire developed by the researcher based on relevant literatures reviewed [16-18]. The instrument comprised of two sections: Section A, covers Socio demographic characteristic of the students while Section B, covers challenges of using information and communication technology.

\subsection{Setting}

This study was conducted in Faculty of Nursing, Tanta University, Egypt. Tanta University is an Egyptian university in the city of Tanta, Al Gharbiyah governorate, Egypt. The 
university is under the direct scientific supervision of the Ministry of Higher Education. It was founded first in 1962 as a branch from the University of Alexandria with the faculty of Medicine only and then it became an independent university named University of the Middle Delta in 1972. It had at that time Medicine, Science, Agriculture and Education faculties. Then, its name was changed into Tanta University in 1973. The university's branch in Kafr ash Shaykh was constituted in 1983. In 1976, the ministerial decree No. 642 was issued in order to identify Tanta University faculties and institutions including Higher Institute of Nursing. Then the presidential decree No. 200 was issued in 2000 to turn nursing institutions in Egyptian universities to independent colleges in which period of study lasts for 4 years qualifying students to be graduated with a bachelor degree of nursing. Later the internal bylaw of the faculty of Nursing was issued upon the ministerial decree No.966 on 9th July 2000 [19].

\subsection{Target Population}

All the nursing students at $4^{\text {th }}$ year, who enrolled in the academic year 2015/2016 and registered for the community health nursing courses, were included in the study. Their number was 600 students. The response rate was $84 \%, 504$ students were involved in the study.

\subsection{Sample Size and Sampling Technique}

A purposive sampling technique was used where all the final year $\left(4^{\text {th }}\right.$ Year) students were used for the study. A sample size of 600 was used with $84 \%$ response rate.

\subsubsection{Inclusion Criteria}

Only $4^{\text {th }}$ year students were included in this study. This was because E-learning courses and nursing informatics courses were only offered at $4^{\text {th }}$ year of the undergraduate studies.

\subsubsection{Exclusion Criteria}

All students below $4^{\text {th }}$ year were excluded from the study for lack of experiences in e-learning and other ICT related information and skills.

\subsection{The Pilot Study}

A pilot study was carried out on 60 students to test the clarity, applicability of the tool and to estimate the length of time needed to complete data collection from each student as well as to identify any obstacle or problems in data collection. These 60 students were not included in the study sample and all the necessary modifications were made according to the pilot findings. Internal consistency test was used to check the reliability of the instrument where Cronbach's alpha value of $0.798(>.7000)$ was obtained which shows that the instrument is reliable.

\subsection{Ethical and Legal Considerations}

Before conducting the study, official permission was obtained from the Dean of the Faculty of Nursing and the Head of department of community health nursing. An informed consent for participation in the study was obtained from the entire sample. The study was not expected to cause any harm and/or pain to the respondents. Confidentiality and privacy of respondents was considered regarding the data collected.

\subsection{Data Analysis}

The data collected were organized, tabulated and statistically analysed using Statistical Package for Social Science (SPSS) 20. Mean, Standard deviation and Chi-square were calculated. 95\% Confidence Interval was used with $\mathrm{P}$ value $<0.05$ considered significant.

\subsection{Limitation of the Study}

The response rate of this study was $84 \%$ (504 students), therefore the analysis and the results were presented based on this sample size. Only questionnaires found to be at least $85 \%$ completed were considered for the analysis.

\section{Results}

The result of this study as indicated by Table 1 showed the distribution of the respondents by socio-demographic characteristics. The table indicated that the mean age of the respondent was $21.45 \pm 0.69$ years. The table also illustrated that the majority $(83.5 \%)$ of the respondents were females. The table showed that about two fifth (41.1\%) of the respondents fathers had secondary education and slightly more than one third $(35.5 \%)$ had university education and above. About half (48.5\%) of the respondents mothers had secondary education and only 20.4 percent had university education and above. Concerning the fathers' occupation, $46.0 \%$ were employees while $65.3 \%$ of the respondents' mothers were housewives. The table also revealed that $53.0 \%$ of the study sample had enough and saving with respect to the family income and $61.3 \%$ lived in the rural areas.

Table 1. Distribution of the respondents by socio-demographic characteristic.

\begin{tabular}{lll}
\hline \multirow{2}{*}{ Socio-demographic characteristics } & $(\mathbf{n = 5 0 4 )}$ & \\
\cline { 2 - 3 } & $\mathbf{N}$ & $\mathbf{\%}$ \\
\hline Age in years: & 19 & 3.8 \\
20 & 276 & 54.8 \\
21 & 172 & 34.1 \\
22 & 37 & 7.3 \\
23 and above & $20-24$ & \\
Range & $21.45 \pm 0.69$ & \\
Mean \pm SD & & \\
Sex: & 83 & 16.5 \\
Males & 421 & 83.5 \\
Females & & \\
Fathers' education: & 60 & 11.9 \\
Illiterate, read \& write & 58 & 11.5 \\
Elementary education & 207 & 41.1 \\
Secondary education & 179 & 35.5 \\
University education \& above & & \\
Mothers' education: & & \\
\hline
\end{tabular}




\begin{tabular}{lll}
\hline \multirow{2}{*}{ Socio-demographic characteristics } & $(\mathbf{n}=\mathbf{5 0 4})$ \\
\cline { 2 - 3 } & $\mathbf{N}$ & $\mathbf{\%}$ \\
\hline Illiterate, read \& write & 112 & 22.2 \\
Elementary education & 44 & 8.7 \\
Secondary education & 245 & 48.5 \\
University education \& above & 103 & 20.4 \\
Fathers' occupation: & & \\
Professionals & 111 & 22.0 \\
Employees & 232 & 46.0 \\
Technical & 15 & 3.0 \\
Workers & 50 & 9.9 \\
Farmers & 48 & 9.5 \\
Private work & 48 & 9.5 \\
Mothers' occupation: & & \\
Housewives & 329 & 65.3 \\
Professionals & 85 & 16.9 \\
Employees & 73 & 14.5 \\
Workers & 7 & 1.4 \\
Farmers & 6 & 1.2 \\
Private work & 4 & 0.8 \\
Family income: & & \\
Enough and save & 267 & 53.0 \\
Just enough & 213 & 42.3 \\
Not enough & 24 & 4.8 \\
Place of residence: & & \\
Rural & 309 & 61.3 \\
Urban & 195 & 38.7 \\
\hline
\end{tabular}

Table 2. Distribution of the respondents by challenges faced in utilizing ICT.

\begin{tabular}{lll}
\hline \multirow{2}{*}{ Challenges* } & $(\mathbf{n}=\mathbf{5 0 4})$ \\
\cline { 2 - 3 } & $\mathbf{N}$ & $\mathbf{\%}$ \\
\hline Slow/poor internet speed or access & 425 & 84.3 \\
Lack of ICT facilities. & 405 & 80.4 \\
Searching on the internet is time consuming & 366 & 72.6 \\
No or poor motivation from the faculty member & 365 & 72.4 \\
Electricity problem & 354 & 70.2 \\
Problems in locating authentic Information & 354 & 70.2 \\
Required information is not easily accessible & 346 & 68.7 \\
Expensive internet subscription & 345 & 68.5 \\
Lack of necessary skills in using the ICD devices & 284 & 56.3 \\
Lack of information searching skills & 269 & 53.4 \\
Lack of necessary skills in using internet & 254 & 50.4 \\
\hline
\end{tabular}

*More than one response was allowed.

Table 2 showed the distribution of the respondents according to the challenges faced during ICT utilization. The table indicated that most $(84.3 \%$ and $80.4 \%)$ of the students attributed their challenge to slow or poor internet speed or access and lacked ICT facilities respectively. Less than three quarters $(72.6 \%, 72.4 \%, 70.2 \%$ and $70.2 \%)$ of the students indicated that searching on the internet was time consuming, lack of or poor motivation from the faculty members, electricity problem and problems in locating authentic information are the challenges they faced respectively. The table also revealed that slightly more than two thirds $(68.7 \%$ and $68.5 \%$ ) of the respondents stated that they challenges they faced include lack of easy access to the required information and expensive internet subscription respectively; moreover, $56.3 \%$ of respondents lacked the necessary skills in using ICT devices, $53.4 \%$ of them showed that lack of skills in searching information was their challenge and finally, $50.4 \%$ of them stated that lack of necessary skills in using the internet was their main challenge.
Table 3 below, showed the relationship between respondent's place of residence and challenges faced in using ICT. The table illustrated that although the percentages of rural resident respondents who reported challenges faced in using ICT exceeded that of urban resident respondents, there was no statistical relationship between place of residence and all the studied variables related to challenges except for deficiency in easy access to the required information $(\mathrm{P}=0.032)$.

Table 3. Relationship between place of residence and challenges faced in using ICT.

\begin{tabular}{|c|c|c|c|c|c|c|}
\hline \multirow{3}{*}{$\begin{array}{l}\text { Challenges faced by } \\
\text { students }\end{array}$} & \multicolumn{4}{|c|}{ Place of residence $n=504$} & \multirow{3}{*}{$\mathbf{X}^{2}$} & \multirow{3}{*}{$\mathbf{P}$} \\
\hline & \multicolumn{2}{|c|}{$\begin{array}{l}\text { Rural } \\
(\mathrm{n}=309)\end{array}$} & \multicolumn{2}{|c|}{$\begin{array}{l}\text { Urban } \\
(\mathrm{n}=195)\end{array}$} & & \\
\hline & $n$ & $\%$ & $\mathbf{N}$ & $\%$ & & \\
\hline Lack of ICT facilities & 241 & 88.0 & 164 & 84.1 & 2.827 & 0.093 \\
\hline $\begin{array}{l}\text { Lack of necessary skills in } \\
\text { using ICT devices }\end{array}$ & 181 & 41.4 & 92 & 47.2 & 1.610 & 0.204 \\
\hline $\begin{array}{l}\text { Poor motivation from the } \\
\text { faculty members }\end{array}$ & 227 & 73.5 & 138 & 70.8 & 0.434 & 0.510 \\
\hline Electricity problems & 281 & 70.6 & 136 & 69.7 & 0.037 & 0.847 \\
\hline Slow/poor internet speed & 262 & 84.8 & 163 & 83.6 & 0.130 & 0.718 \\
\hline $\begin{array}{l}\text { Expensive internet } \\
\text { subscription }\end{array}$ & 214 & 69.3 & 131 & 67.2 & 0.239 & 0.625 \\
\hline $\begin{array}{l}\text { Lack of necessary skills in } \\
\text { using internet }\end{array}$ & 156 & 50.5 & 98 & 50.3 & 0.003 & 0.960 \\
\hline $\begin{array}{l}\text { Problems in locating } \\
\text { authentic information }\end{array}$ & 220 & 71.2 & 134 & 68.7 & 0.352 & 0.553 \\
\hline $\begin{array}{l}\text { Lack of information } \\
\text { searching skills }\end{array}$ & 168 & 54.4 & 101 & 51.8 & 0.318 & 0.573 \\
\hline $\begin{array}{l}\text { Searching on internet is time } \\
\text { consuming }\end{array}$ & 227 & 73.5 & 139 & 71.3 & 0.286 & 0.593 \\
\hline $\begin{array}{l}\text { Required information is not } \\
\text { easily accessible }\end{array}$ & 223 & 72.2 & 123 & 63.1 & 4.591 & $0.032 *$ \\
\hline
\end{tabular}

*Significant $(\mathrm{P}<0.05)$

\section{Discussion}

The findings of this study revealed that the majority of the students were females within the age range of 20-24 years (Table 1). This may be due to the setting of this study where most of the students were females in the Faculty of Nursing. This finding is in agreement with the finding of Khan et al (2011), who stated that the majority of the respondents were between 20 to 25 years old and most of the respondents were females [20]. The socio-demographic section of the study also revealed that about three quarters of the students' fathers and two thirds of their mothers had secondary education and above (Table 1). This parents' level of education could influence positively the students' use of ICT. Majority of the students' fathers were either professionals or employees while most of their mothers were housewives, which is the custom of Egyptian women in rural area. This study also showed that about one half of the students reported that their family income was enough and can save while almost two thirds of them resided in the rural areas. This finding may be due to the location of Tanta University in the agricultural zone of Egypt. This result is in contrast to the finding of Karaman (2011), who studied 
the nurses' perception of online continuing education; he stated that "of the 1041 responding nurses, $33 \%$ worked and resided in rural settings and $67 \%$ worked and resided in urban areas" [21].

The results of this study indicated that the majority of the students reported that slow or poor internet speed and lack of ICT facilities were the major challenges they faced (Table 2). This finding may be due to the fact that most of the students used mobile smart phones as their sources of internet accessibility rather than high band network such as Wi-fi. This result is in agreement with the finding of Khan et al., (2011), who studied the use of ICT by students of the Faculty of Education at Islamic University of Bahawalpurand. They reported that the majority of the students faced a slow speed of personal computers due to virus, inadequate number of computers in laboratory, lack of time to use e-resources, slow internet connectivity, lack of access to printers in library, electricity failure and lack of support from Information Technology staff, [20].

Findings from the study also revealed that lack of time, poor or lack of motivation from faculty members, electricity problem and problem in locating authentic information are the common challenges faced by about seventy percents of students in ICT use (Table 2). A study conducted by Hussain, Iqbal, and Akhtar (2010), on public universities in Islambad, Pakistan revealed that teaching through technology based learning environment enhanced the achievement level of the students. To create good faculties with ICT resources will take substantial financial resource allocation from the national budget, spent more strategically, with strong political commitment of government to ensure equity and universal access to education. However, in the situation where the required infrastructure such as electricity and standard ICT centers are not available, teachers are incapacitated in using computer to facilitate effective teaching and learning processes [22].

From this present study, it was noted that students who reside in rural areas were significantly faced by the challenges of lack of ICT devices, electricity problems, slow or poor internet speed, problems in locating an authentic and required information while students from the urban areas were faced more with the challenges of expensive internet subscription and lack of necessary skills in using ICT devices (Table 3).

\section{Conclusion and Recommendation}

From this study, it can be concluded that the most frequent challenges faced by the students during information and communication technology utilization were slow/poor internet access and lack of ICT facilities. Others stated that the challenges faced include searching on the internet is time consuming, poor motivation from the faculty members, electricity problem and problems in locating authentic information. Although rural resident students reported more challenges in using ICT, there was no statistical relationship between place of residence and all the challenges except for deficiency in easy access to the required information. Therefore, based on the findings of this study, it is recommended that the faculty and the university management should ensure adequate provision and proper maintenance of ICT devices to the students with corresponding accessibility. Furthermore, the level of computer literacy and competency in ICT skills use should be enhanced by integrating ICT courses into the curriculum of undergraduate students and by developing positive attitude towards the application of ICT by all the faculty members.

\section{References}

[1] Fadi A. The Need for effective information security awareness, Journal of Advances in Information Technology, 2012; 3(3): 165-8.

[2] Kokol P. Exploring ICT competencies in a Bologna masters level Nursing program, Online journal of Nursing Informatics, 2012;7(7):1-4.

[3] Bates A. Technology E-learning and distance education. Routing. 2005; 13(2): 121-125.

[4] Davis M. and Harden R. E is for everything in E-Learning. Medical Teacher, 2001; 23(5): 441-444.

[5] Harden R. Development in outline based education. Medical Teacher, 2002; 24(2): 117-20.

[6] Maroof K, Parasher P and Bansal R. How are our Medical Students Using the Computer and Internet? A study from a medical college of North India. Medical Teacher J, 2012; 53(2): 89-93.

[7] Adeolu A. J and Mercy O. Effective utilization and maintenance of ICT facilities for quality teaching and learning outcome in secondary schools in Ondo State, Nigeria, International Journal of Research Studies in Educational Technology, 2013; 2 (2): 27-40

[8] Al-Fadhli S. Students' perceptions of e-learning in Arab society: Kuwait University as a case study. E-Learning and digital media J, 2008; 5 (4): 418-428.

[9] Button D. E-learning \& information communication technology (ICT) in nursing education: A review of the literature, Nurse Education Today, 2013; 1-13 Available at: http://dx.doi.org/10.1016/j.nedt.2013.05.002

[10] Childs S., Blenkinsopp E., Hall A. and Walton G. Effective elearning for health professionals and students; barriers and their solutions. A systematic review of the literature; findings from the HeXL project. Health Information and Libraries Journal, 2005; 22 (2): 20-32. Available at: http:/dx.doi.org/10.1111/j.1470-3327.2005.00614.x

[11] Heinzelmann P. Telemedicine in the future, 2006. In: Wootton $\mathrm{R}$ et al. Introduction to Telemedicine. London, 2006: Royal Society of Medicine Press.

[12] Burmahl B. The big picture. Health facilities management, 2000; 13(9): 16-22.

[13] Sarhan F. Telemedicine in healthcare: the legal and ethical aspects of using new technology. Nursing Times, 2009; 105: $43,18-20$. 
[14] Helitzer D, Heath D, Maltrud K, Sullivan E, and Alverson D. Assessing or predicting adoption of telehealth using the diffusion of innovations theory: A practical example from a rural program in New Mexico. Telemed $J$ E-Health, 2003; 9: 179-187.

[15] Effken J. Health IT-enabled Care for Underserved Rural Populations: The Role of Nursing, Journal of the American Medical Informatics Association, 2009; 16 (4): 439-445.

[16] Bello I. S. Knowledge and utilization of information technology among health care professionals and students in Ile-Ife, Nigeria: A case study of a university teaching hospital. J Med Internet Res., 2004; 6(4): e45.

[17] Malose V. M. Toward developing a self rating scale for assessing Teacher's ICT- integration competencies. A dissertation for master degree, appendix $F$. University of Johannesburg, 2012; 124-133.
[18] Alberta. I. Classroom Assessment Tool Kit for the Information and Communication Technology Program of Studies, Edmonton: Alberta learning cataloguing in publication data, 2003. 37-40.

[19] www.tanta.edu.eg. Retrieved on $2^{\text {nd }}$ October, 2016.

[20] Khan S. A, Bhatti R, and Khan A. A. Use of ICT by students: A survey of faculty of Education at IUB. Journal of Library philosophy and practice, 2011; 1-12.

[21] Karaman S. Nurses' perceptions of online continuing education. BMC Medical Education J. 2011; 11:86.

[22] Hussaain M. A., Iqbal M. Z., and Akhtar M. S. Technology based learning environment and student achievement in English as a foreign language in Pakistan. Journal of World Academy of Science, Engineering, and Technology, 2010; 61: 129-133. 